\title{
GLACIATION OF THE LAKE-DISTRICT.
}

Srr,-In your last number Mr. Mackintosh, in his reply to the letters of my colleague, Mr. Wollaston, and myself, states, with reference to my letter in your number for last December, that any want of theoretical agreement between us consists to a great extent in the application of terms. He also says that I have not substantiated any charge of inaccuracy of observation in his paper pub. lished in your number for last October. Mr. Mackintosh there stated that in the valley of Kentmere "no traces of moraines, except perched and scattered blocks, are to be found."

In my letter I stated my belief that " the old lake, represented by the alluvium of Kentmere, originated partly from damming by a moraine ;" and I also pointed out the occurrence of scratched stones in this valley. The want of theoretical agreement indicated by these two passages does not seem to hinge upon any different " application of terms."

Mr. Mackintosh calls the mounds which occur in the Kentmere valley "an upland extension of the boulder-drift of the plains." On this I make no comment. Boulders do occur in the valley, together with large numbers of scattered blocks, the latter derived from the immediate vicinity. I still, however, retain my belief that these mounds are the remains of moraines. The position of the mounds, the scratched stones, the alluvial flat, and the gravels at the mouth of the valley, all tend to confirm me in this belief. I do not hold the view about the two great valley-ignoring ice-streams at different periods, with which Mr. Mackintosh credits me. I believe the strix transverse to the axes of the valleys were made when the ice was disappearing from the low ground, and that the ice on the fells, being no longer forced to pass in the direction of valley axes by adjacent valleys full of ice, simply gravitated towards the lower ground, probably obliterating in its passage much previously formed striation, and leaving in its stead these later finishing touches, in the same way that a few strokes of a file will obliterate previous file marks made in a contrary direction.

If $\mathrm{Mr}$. Mackintosh does not believe in the existence of moraine stones on the fells in the neighbourhood of Skeggles Water-What then are the scratched stones which are so numerous there? They in every respect resemble ordinary moraine stones, and I feel bound to regard them as such until their markings can be satisfactorily accounted for by some other hypothesis. In conclusion, I may add that it has not been my intention to look for faults in Mr. Mackintosh's paper, but simply to uphold my observations when the statements of Mr. Mackintosh seemed to contradict or ignore them; and I trust that his researches among the northern cliffs may lead him to useful and interesting results.

II. M. Grological Survex,

Frank Rutuey. January 14, 1871. 